Rev. Col. Bras. Cir.

Vol. 34 - № 1: 001, Jan. / Fev. 2007

\title{
ESCOLHA DAS ESPECIALIDADES. ASSUNTO EM DISCUSSÃO
}

\section{SPECIALITY CHOICE. THEME IN DISCUSSION}

\author{
Orlando Marques Vieira-ECBC \\ Ex-Presidente do Colégio Brasileiro de Cirurgiões
}

O número de alunos matriculados nos cursos de medicina é crescente. Em dezembro de 2006, o Brasil tinha 152 escolas médicas em funcionamento e este número tende a aumentar, tendo em vista os vários pedidos para abertura de novas escolas de medicina no Brasil.

A área da saúde é uma das que terá um crescimento real no país. O leque de opções nesta área é imenso e abriga um crescente número de profissionais médicos e de outras áreas ligadas à saúde. Vários procedimentos que surgiram ultimamente implicaram numa demanda importante de médicos, por exemplo, a área do diagnóstico por imagem e a chamada radiologia intervencionista.

No início do Século XX, existiam o clínico e o cirurgião; algumas vezes mesclando-se em seus atendimentos. Ao cirurgião cabia a realização dos chamados procedimentos cirúrgicos. A atuação do cirurgião não tinha limites, desenvolvia suas atividades em todos os seguimentos do corpo humano.

O desenvolvimento científico e a necessidade do emprego de técnicas especiais acarretaram no surgimento dos especialistas. Várias especialidades científicas se desenvolvendo e, nos anos 50, já tínhamos várias áreas reconhecidas.

A especialização representa uma evolução natural dos cirurgiões, alicerçados no progresso da ciência cirúrgica e na propedêutica instrumental. Hoje, vemos serviços dedicados a setores e até a um único órgão, como é o caso de cirurgia cardíaca, cirurgia hepática e até a uma doença, o caso da cirurgia chamada "cirurgia oncológica".

As especialidades eram escolhidas como conseqüência da aptidão e das oportunidades advindas do trabalho contínuo nos serviços médicos, clínicos ou cirúrgicos. $\mathrm{Na}$ cirurgia, a liderança era de importância fundamental e os professores ou chefes acompanhavam o jovem cirurgião no seu desenvolvimento.

A implantação da Residência Médica no Brasil, na década de 50 do Século XX, veio trazer novas possibilidades do aprendizado em serviço e, conseqüentemente, a formação em diversas especialidades, sempre com a regência de um líder.

Como já foi por mim comentado em editorial da Revista do CBC "a Cirurgia Geral certamente permanece como a base da formação cirúrgica e passou-se a denominar de Cirurgião Geral aquele com atuação predominante na parede abdominal, no aparelho digestivo e no trauma”.

Ao cirurgião geral também cabe, ainda hoje, a responsabilidade do atendimento - além de sua rotina - dos casos de emergência do próprio hospital e dos resultantes de pacientes externos com quadros emergenciais traumáticos e não-traumáticos. Michael Choti, responsável pelo Programa de Residência Médica do Johns Hopkins Hospital, observou que somente os residentes de cirurgia geral, neurocirurgia e transplantes são ocupados em $90 \%$ de sua carga horária.

Hoje, é notória a pouca procura pelas especialidades, ou mesmo ramos destas próprias especialidades, que impõem um ritmo de vida calcado nas jornadas árduas e exaustivas.

Deve ser lembrada a presença numérica importante das mulheres exercendo a medicina e, isto, veio mudar o quadro da preferência nas especialidades. Em sua maioria, as mulheres dão preferência às áreas de trabalho que possam compatibilizar a profissão com sua vida pessoal.

O Professor Erlo Roth, professor em Chicago, em conferência na Academia Nacional de Medicina, deixou claro, ao falar sobre Ensino de Graduação Médica nos Estados Unidos da América, que os alunos têm, hoje, uma preferência bem definida para os ramos da medicina que lhes assegurem uma boa qualidade de vida e um bom mercado de trabalho; em conseqüência disso, várias especialidades caminham para uma procura preferencial escassa.

Garantia de trabalho futuro é uma meta justa dos nossos estudantes. Por outro lado, é preciso chamar a atenção das autoridades, e mesmo das instituições médicas, da necessidade do incentivo às áreas que hoje não se revelam preferenciais. Neste momento, é notório o decréscimo na escolha para Cirurgia Geral, Cardíaca, Transplantes e Neurocirurgia. Mas estas especialidades não podem prescindir do apoio, de várias formas, que mantenham o funcionamento progressivo e não, a estagnação.

A cirurgia progride como um todo e certas especialidades, necessariamente, precisam ser lembradas para serem incentivadas e recompensadas. 